\title{
SLUDGE REDUCTION BY UNCOUPLING METABOLISM: SBR TESTS WITH PARA-NITROPHENOL AND A COMMERCIAL UNCOUPLER
}

\author{
E. Zuriaga-Agustí ${ }^{1 *}$, J.A. Mendoza-Roca ${ }^{1}$, A. Bes-Piá ${ }^{1}$, J.L. Alonso ${ }^{2}$, I. Amorós ${ }^{2}$ \\ ${ }^{1}$ Instituto de Seguridad Industrial, Radiofísica y Medioambiental, Universitat Politècnica de \\ València. Camino de Vera s/n 46022 Valencia (Spain) \\ ${ }^{2}$ Instituto Ingeniería del Agua y Medio Ambiente, Universitat Politècnica de València, \\ Camino de Vera s/n 46022 Valencia (Spain) \\ Tel. +34963876386; Fax+34963877639; e-mail*: elzuag@etsii.upv.es
}

\begin{abstract}
Nowadays cost reduction is a very important issue in wastewater treatment plants. One way, is to minimize the sludge production. Microorganisms break down the organic matter into inorganic compounds through catabolism. Uncoupling metabolism is a method which promote catabolism reactions instead of anabolism ones, where adenosine triphosphate synthesis is inhibited. In this work, the influence of the addition of para-nitrophenol and a commercial reagent to a sequencing batch reactor (SBR) on sludge production and process performance has been analysed. Three laboratory SBRs were operated in parallel to compare the effect of the addition of both reagents with a control reactor. SBRs were fed with synthetic wastewater and were operated with the same conditions. Results showed that sludge production was slightly reduced for the tested para-nitrophenol concentrations (20 and $25 \mathrm{mg} / \mathrm{L}$ ) and for a LODOred dose of $1 \mathrm{~mL} /$ day. Biological process performance was not influenced and high COD removals were achieved.
\end{abstract}


Keywords: Wastewater treatment; Cell disruption; Viability; Sludge reduction; Metabolic uncoupler.

\section{Introduction}

Reduction of the sludge production in a municipal wastewater treatment plant (MWWTP) is very important because it implies a diminution in the costs of secondary sludge management (50-60\% of the total operation costs of sewage treatment plants) [1]. Moreover, European legislation requires that wastewaters receive biological treatment before discharging (91/2711EEC, 1991), what implies the production of biological sludge in most of the MWWTP.

In order to decrease the sludge production, the enhancement of the endogenous metabolism is widely used in WWTPs, increasing the sludge retention time. However, this method is very limited. Sludge cycling between aerobic, anoxic and anaerobic conditions also drives to sludge diminution [2-4]. Other mechanisms to reduce the sludge production can be performed: cell lysis plus cryptic growth (different technologies have been used for it based on cell lysis plus cryptic growth, like physical, chemical, thermal or oxidative treatments) [5-8], uncoupled metabolism, microbial predation and hydrothermal oxidation $[9,10]$.

Microorganisms remove organic matter from wastewater by means of metabolic reactions. Specifically, by means of catabolism reactions, organic substances are broken down into inorganic compounds $\left(\mathrm{CO}_{2}\right.$ and $\left.\mathrm{H}_{2} \mathrm{O}\right)$. Energy released in these reactions is used to create new microorganisms (anabolism reactions). In the present work, uncoupled metabolism has been studied. 
Metabolic uncouplers [11] are substances that promote catabolic reactions in microorganisms against those of anabolism (cell production). In the presence of these compounds, most of the organic matter is oxidized preferably to carbon dioxide, not being used in the synthesis of new cell material due to the fact that synthesis of adenosine triphosphate (ATP) is prevented. Different metabolic uncouplers have been used. Low et al., (2000) [12] concluded that a reduction in biomass production could be achieved by increasing the specific absorption rate of the substrate. They achieved $49 \%$ biomass reduction with a para-nitrophenol (pNP) concentration of $120 \mathrm{mg} / \mathrm{L}$. Other chemicals used are 3,3',4',5-tetrachlorosalicylanilide (TCS) [13] and 2,4,5trichlorophenol (TCP), which achieved reductions of 78\% and 50\%, respectively [14]. Fang et al. (2015) [15] studied the influence of three metabolic uncouplers (pchlorophenol (pCP), o-chlorophenol (oCP) and o-nitrophenol (oNP)) on excess sludge reduction. Results showed that sludge was reduced by $58.2 \%, 59.8 \%$ and $80.8 \%$, respectively, at concentrations of $20 \mathrm{mg} / \mathrm{L}$. The problem that could appear with some uncouplers is that they can diminish COD removal performance by toxicity effects on a part of the biomass.

To overcome the limitations of current uncouplers, several innovative substitutes like LODOred have been developed. LODOred is a commercial product that enhances endogenous respiration. It enwraps microorganisms and leads to the formation of compact activated sludge flocs. Its composition is based on vitamins, enzymes and other additives. However, there is no detailed information available on this chemical. It is known that it is not a hazardous chemical unlike pNP. Therefore, in this study, different two concentrations of pNP and the recommended by the supplier LODOred concentration were tested in order to study the sludge reduction and the influence on the biological process performance. The treatment proposed was carried out in three 
laboratory scale sequencing batch reactors, fed with synthetic wastewater. The advantage of SBR process is that operates in cycles, each one with four phases: fill, react (aerobic), settle and draw. After the start-up one SBR was operated as control reactor, whereas the LODOred and para-nitrophenol were added to the other SBRs.

\section{Material and Methods}

\subsection{Simulated municipal wastewater}

SBRs feed solution consisted of $360 \mathrm{mg} / \mathrm{L}$ of bacteriological peptone, $360 \mathrm{mg} / \mathrm{L}$ of meat extract (both of Cultimed, Panreac) and $49 \mathrm{mg} / \mathrm{L}$ of tri-sodium phosphate 12hydrate (Panreac). Chemicals were dissolved in tap water. COD of the simulated wastewater was $800 \mathrm{mg} / \mathrm{L}$.

\subsection{Operation of the laboratory SBRs}

Three SBRs were operated in parallel (as shown in Figure 1) and fed with the same simulated wastewater. They were seeded with activated sludge taken from a municipal wastewater treatment plant (WWTP). The time required for adapting the sludge from a municipal wastewater treatment plant to the simulated wastewater was only 7 days.

SBR 1 was used as the control reactor, para-nitrophenol was dosed daily to the SBR 2 (two doses of 20 and $25 \mathrm{mg} / \mathrm{L}$ were tested), and $110 \mathrm{mg} / \mathrm{L}$ of the commercial reagent LODOred (BIOAZUL) was dosed in SBR 3. Chemicals were added directly to the SBR in the first cycle of the day.

The operation of the SBRs was always carried out according to the data of Table 1 . The volume exchange ratio (VER) is defined as the quotient between the volume fed 
in each cycle and the total reaction volume $\left(\mathrm{V}_{\mathrm{R}}\right)$. The hydraulic retention time is defined for SBR as in continuous flow activated sludge systems $\left(V_{R} / Q\right)$, where $Q$ is the daily influent flow rate.

Table 1. Strategy of SBR operation: phases duration and operating parameters.

\begin{tabular}{lc}
\hline Cycle steps & Duration \\
\hline Anoxic fill phase & $0.5 \mathrm{~h}$ \\
Anoxic reaction phase & $0.5 \mathrm{~h}$ \\
Aerobic reaction phase & $5.2 \mathrm{~h}$ \\
Settling phase & $1.5 \mathrm{~h}$ \\
Draw phase & $0.2 \mathrm{~h}$ \\
Idle phase & $0.1 \mathrm{~h}$ \\
Total cycle time & $8 \mathrm{~h}$ \\
Food/Microorganisms ratio & $0.34 \mathrm{kgCOD} / \mathrm{kgLMSS} \cdot \mathrm{d}$ \\
Volume exchange ratio (VER) & $1 / 2$ \\
Hydraulic retention time (HRT) & $0.67 \mathrm{~d}$ \\
\hline
\end{tabular}

Sludge withdrawals were performed periodically by draining the volume of mixed liquor necessary for achieving a concentration of MLSS of $2.5 \mathrm{~g} / \mathrm{L}$. 


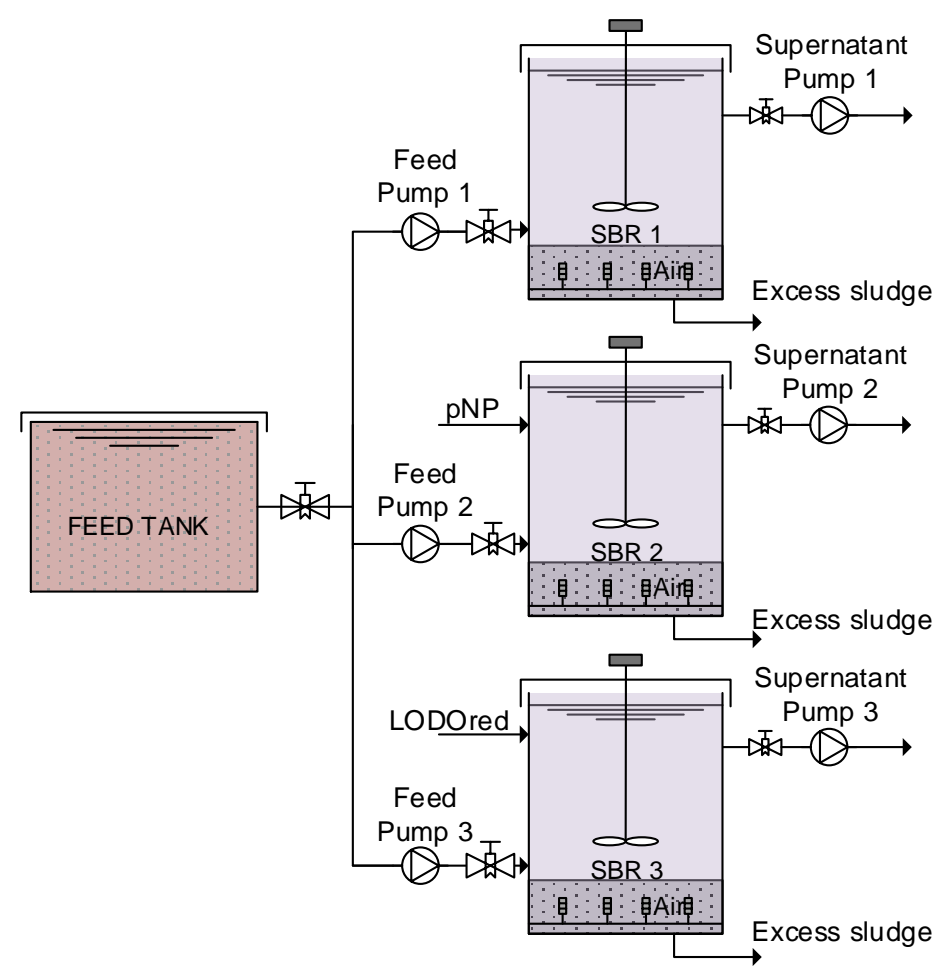

Figure 1. Scheme of the laboratory sequencing batch reactors

\subsection{Mixed liquor characterization}

Mixed liquor suspended solids and volatile suspended solids (MLSS and MLVSS) were determined every day (in duplicate) according to APHA, 2005 [16]. COD removal was determined daily by means of cell tests from Merck. Dissolved oxygen, $\mathrm{pH}$ and conductivity were also monitored with OXI 330, EC-Meter (GLP-31+) and pH-Meter (GLP-21+) from CRISON, respectively.

In order to study if cell disruption occurs, DNA, was analyzed periodically in the effluent. Quant-itTM dsDNA HS (Invitrogen) assay kit was used to determine DNA. Protein and carbohydrates in the effluent were measured as main components of the soluble microbial products (SMP). SMP concentrations can be related to bacterial stress among other causes. Protein and carbohydrates analyses were carried out applying BCA and Anthrone methods, respectively. Bovine serum albumin (BSA) 
(Sigma-Aldrich) and glucose (Panreac) were used as the protein and carbohydrate standards.

Membrane integrity was estimated by using the LIVE/DEAD ${ }^{\circledR}$ BacLight $^{\mathrm{TM}}$ bacterial viability kit (Molecular Probes). It contains two fluorochromes, Syto 9 (green), which is a small molecule that can get into intact plasma membranes and propidium iodide (red), which is a larger molecule that penetrates only compromised membranes [17]. Viable cells result in green color while damaged cells result in red color. Samples were evaluated with a BX50F microscope (Olympus, Tokyo, Japan) equipped with a 100-W high-pressure mercury lamp. The software used to analyze the images was BioImageL ${ }^{\mathrm{TM}}$ v.2.1.

\subsection{Respirometric test for biomass yield determination and toxicity}

Respirometry is based on the oxygen consumption by the microorganisms from the activated sludge. Respirometry tests were carried out in a BM-Advance analyzer from SURCIS. The reactor vessel was filled with $1 \mathrm{~L}$ of activated sludge from the SBR, previously aerated during $24 \mathrm{~h}$ to obtain endogenous conditions in the biomass. A dynamic experiment was performed by continuous stirring, aeration and recirculation between both sides of the vessel by means of a peristaltic pump, where the dissolved oxygen was continuously measured. Temperature was kept constant at $22^{\circ} \mathrm{C}$ during the experiment through a Peltier cooler module. The heterotrophic biomass yield coefficient $\left(\mathrm{Y}_{\mathrm{H}}\right)$ was calculated by Eq. 1 .

$$
Y_{H}=1-\frac{O C}{C O D_{\text {sodium acetate }}}
$$


Where OC is the oxygen consumed by the microorganisms to biodegrade a substrate. To determine the OC a dynamic respirometry test was performed by adding a sodium acetate solution of $400 \mathrm{mg} / \mathrm{L}(\mathrm{COD}=300 \mathrm{mg} / \mathrm{L})$.

The toxicity of para-nitrophenol was carried out by adding different doses of pNP (every dose led to a pNP concentration increase of $25 \mathrm{mg} / \mathrm{L}$ ) to an activated sludge from a MWWTP fed with sodium acetate as substrate $(0.5 \mathrm{~g} / \mathrm{gVSS})$. Thus, the bacterial activity was evaluated. In order to inhibit the nitrification process, $3 \mathrm{mg}$ of $\mathrm{N}$-allythiourea per gram of MLVSS was added to the activated sludge.

\section{Results and Discussion}

\section{1.para-Nitrophenol toxicity tests}

In order to ensure that the selected pNP concentration was not harmful for the biomass, one liter of sludge from MWWTP was subjected to a toxicity test by continuous addition of pNP doses. Results can be observed in Fig. 2, where the respiration rate $(\mathrm{Rs})$ is depicted.

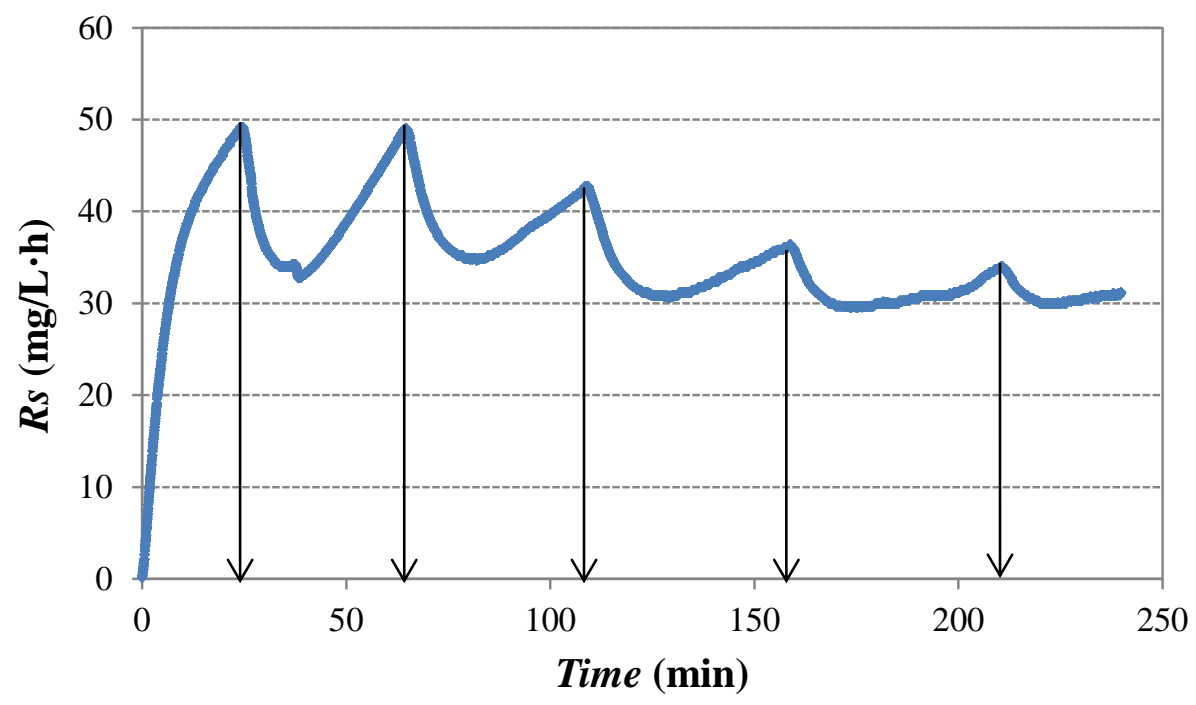

Figure 2. para-Nitrophenol toxicity test 
According to the procedure, after $4 \mathrm{~h}$ of experiment the pNP concentration in the respirometry vessel increased up to $125 \mathrm{mg} / \mathrm{L}$. Results showed that with the concentration tested in the experiments $(25 \mathrm{mg} / \mathrm{L})$, a negligible toxic impact on the activated sludge occurred, since the same maximum respiration rate was achieved again after the first dose of pNP. However, $125 \mathrm{mg} / \mathrm{L}$ of pNP led to an activity decrease of $28.98 \%$ of the activated sludge activity. Ricco et al. (2004) [18] obtained higher toxicity values assessing the toxicity of pNP by respirometric tests measuring the decay of the specific oxygen uptake rate with the pNP concentration. Thus, these authors reported 17.62 and $46.4 \%$ of activity decay for pNP concentrations of 16 and 128 mg/L, respectively. Rezouga et al. (2009) [19] also obtained similar results. These authors reported an OUR decay of approximately $33 \%$ after having added $90 \mathrm{mg} / \mathrm{L}$ of COD of $\mathrm{pNP}$.

Concerning LODOred toxicity, it has to be mentioned that no impact on the biomass was observed in the respirometric analysis.

\subsection{Sludge production in the SBRs}

In Figure 3 the sludge production of the three reactors is shown. Each bar corresponds to the biomass increase between sludge withdrawals in terms of mass production, taking into account a $6 \mathrm{~L}$ of reaction volume. It has to be commented that MLVSS remained around $90 \%$ of the MLSS during the SBRs operation time. 


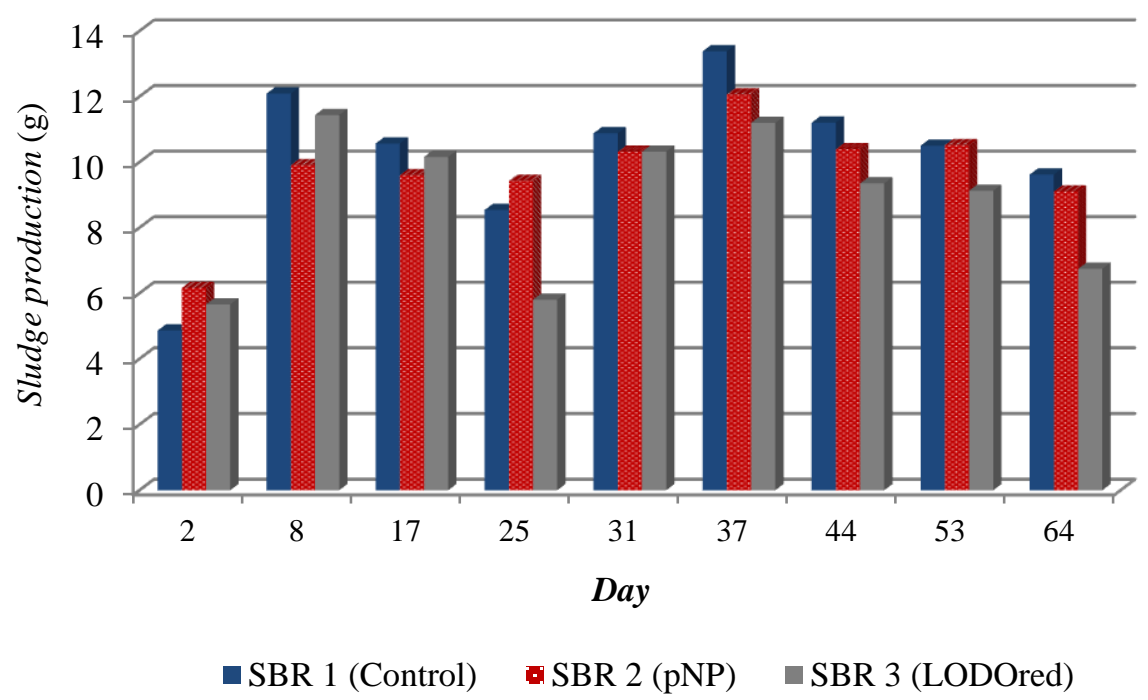

Figure 3. Sludge production between withdrawals during the SBRs operation time

It can be observed that for all SBRs, the sludge production was not steady in the period studied. At the beginning of the SBRs operation, the sludge production was low due to the process start-up, in which the microorganisms were adapted to the new conditions. After the acclimation period, the sludge production increased in all cases. From the 8th day, sludge production between withdrawals was not constant. They ranges between 8.5-13.3 g, 9.1-12 $\mathrm{g}$ and 5.8-11.4 g, for SBR 1, SBR 2 and SBR 3, respectively.

If the obtained results of the three reactors are compared, SBR 1 produced, in general, more sludge than the others. This result was expected since no reagent was added to the reactor. Regarding SBR 2 and SBR 3, a reduction of sludge production was observed especially when the chemical LODOred was added. For this chemical, a sludge reduction of $26.2 \%$ was achieved after 64 operating days. This can be due to the enhancement of the catabolic reactions from endogenous organic matter by hindering the availability of external organic substances. This was observed macroscopically by the decrease of the sludge volume index, that was always lower 
than $100 \mathrm{~mL} / \mathrm{g}$ in the case of the mixed liquor of SBR 3. On the contrary, SVI ranged between 100 and $120 \mathrm{~mL} / \mathrm{g}$ in the other SBRs.

pNP seemed not to be as effective as LODOred and the sludge production was in general lower than the control SBR (SBR 1). This fact could be due to the tested pNP concentration that did not affect the metabolism of most of microorganisms. The $\mathrm{pNP}$ concentration was not increased due to a residual pale yellow color observed in the SBR 2 effluent caused by this chemical.

\subsection{Effluent characteristics and characterization of the mixed liquor}

The main characteristics of the SBRs supernatants (average values) are shown in Table 2.

Table 2. Characteristics of SBR effluent

\begin{tabular}{ccccc}
\hline \multirow{2}{*}{ SBR } & pH & $\begin{array}{c}\text { Conductivity } \\
(\mu \mathrm{S} / \mathrm{cm})\end{array}$ & $\begin{array}{c}\text { COD }(\mathrm{mg} / \mathrm{L}) \\
\text { Initial Period }\end{array}$ & Final Period \\
\hline SBR 1 & 8.16 & 1555 & 27.3 & 38.6 \\
SBR 2 & 8.13 & 1590 & 30.8 & 40.5 \\
SBR 3 & 8.22 & 1616 & 29.5 & 31.7 \\
\hline
\end{tabular}

Table 2 collects the values of $\mathrm{pH}$, conductivity and organic matter (COD) in the effluent at the initial and final operation time. It can be observed that the quality of the effluent in the three reactors was very similar and the measured parameters remained constant during all the experiments. It has to be highlighted that the COD removal was very high, reaching a value of $96 \%$ in all cases. These results showed that the chemicals did not interfere in the biological process performance, in contrast to the results reported by [1]. This author stated that uncoupler application for sludge reduction caused diminution of COD removal, increase of the oxygen consumption and worse activated sludge properties such as settling and dewatering. Other authors 
[20], found that COD removal efficiency was lowered around $13.2 \%$ by adding 20 $\mathrm{mg} / \mathrm{L}$ of nitrophenol.

Figure 4 depicts protein and DNA concentrations in the SBRs effluents. Assuming that the organic matter of the synthetic wastewater was almost completely degraded, the measurement of proteins and DNA were carried out to study if cell lyses occurred.

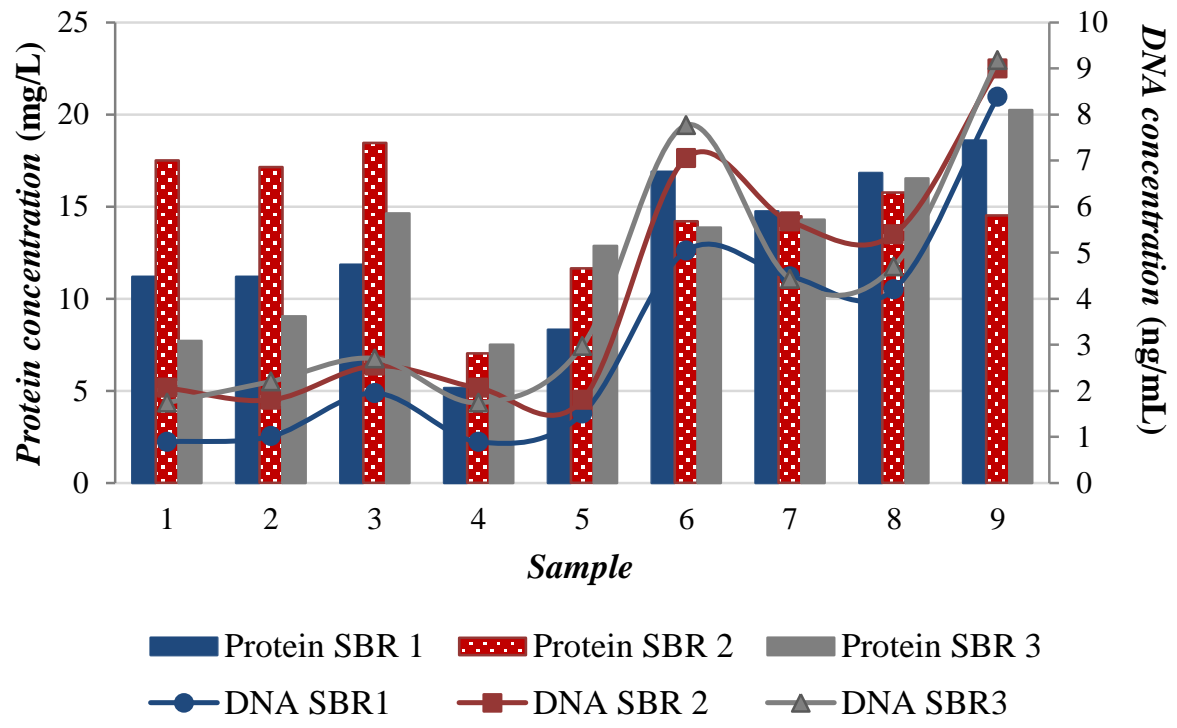

Figure 4. Protein and DNA concentration in the SBRs effluent

It can be observed that protein concentration was quite similar in the SBRs. For the first samples, the highest protein concentrations were obtained for SBR2 containing pNP. It agrees with the lower sludge production in comparison with SBRs 1 and 3 observed in Figure 3 during the first weeks of the experiment. After $25^{\text {th }}$ day, it seems that microorganisms were adapted to the $\mathrm{pNP}$, since cell lysis was not so significant as in the first weeks.

Related DNA concentration, it can be observed that the higher protein concentration the higher DNA concentration analyzed. This result, common to all effluents, may confirm that cell lysis occurred at a certain extent and the measured proteins came 
from the intracellular material of the bacteria. In addition, for all SBRs, carbohydrate concentration values were below $1 \mathrm{mg} / \mathrm{L}$. This fact could be explained both by the characteristics of the influent and by the higher assimilation of carbohydrates by the microorganisms compared with proteins.

Finally, cellular viability tests were carried out. Table 3 collects the percentage of damaged cells. Uncertainty was also calculated as the standard deviation divided by the square root of the number of samples.

Table 3. Comparison in dead cells percentage in the three SBRs

\begin{tabular}{ccc|cc}
\cline { 2 - 5 } & \multicolumn{2}{c|}{ Day 7 } & \multicolumn{2}{c}{ Day 35 } \\
\cline { 2 - 5 } & \% Damaged cells & Uncertainty & \% Damaged cells & Uncertainty \\
\hline SBR 1 & 9.82 & 0.22 & 10.78 & 0.59 \\
SBR 2 & 11.07 & 0.97 & 12.25 & 0.11 \\
SBR 3 & 7.61 & 0.81 & 9.42 & 0.49 \\
\hline
\end{tabular}

Table 3 shows that, for the three SBRs, the percentage of damaged cells was quite low and it was not observed significant differences between SBR1 (control) and SBR2 and SBR3. In addition, this tendency remained stable with the operation time, since the damaged cells percentage slightly varied. These results might indicate that the uncoupler pNP and the commercial product did not interfere on cells viability which confirms the optimal performance of the biological process. It agrees with the limited cell lyses explained above.

In Figure 5, some microscope pictures taken from the mixed liquor in different times are shown as an example. No significant differences have been found between day 7 and day 35. As it can be observed, the total green and red areas kept almost constant, what corresponds with the results collected in table 3. 
Day 7
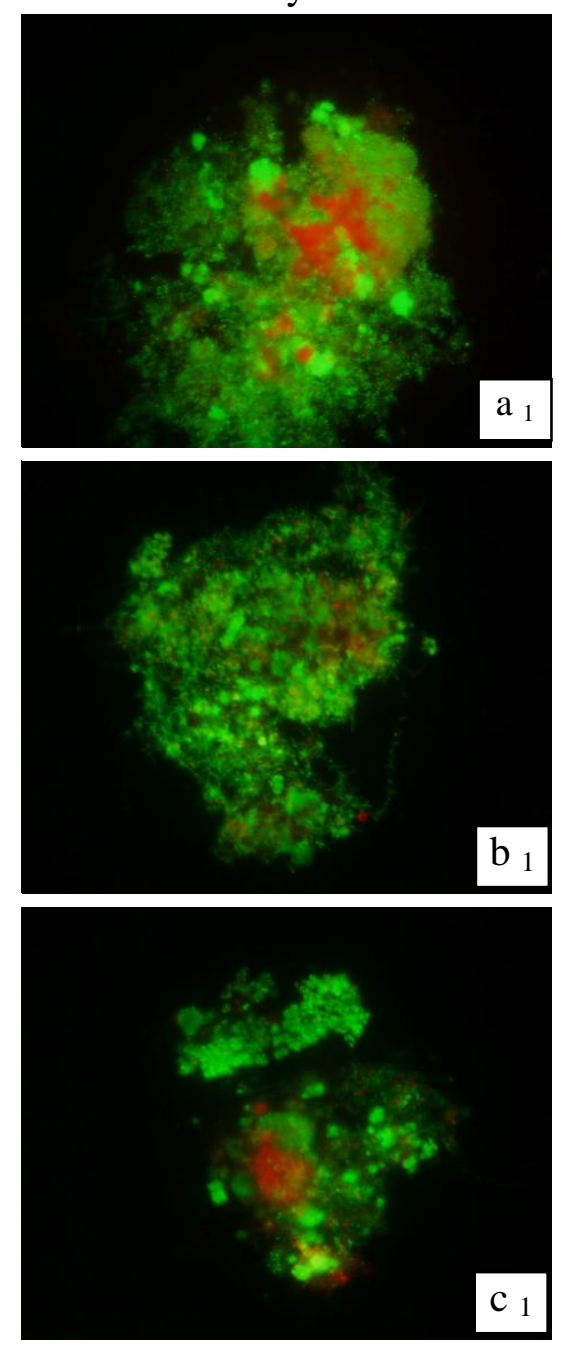

Day 35
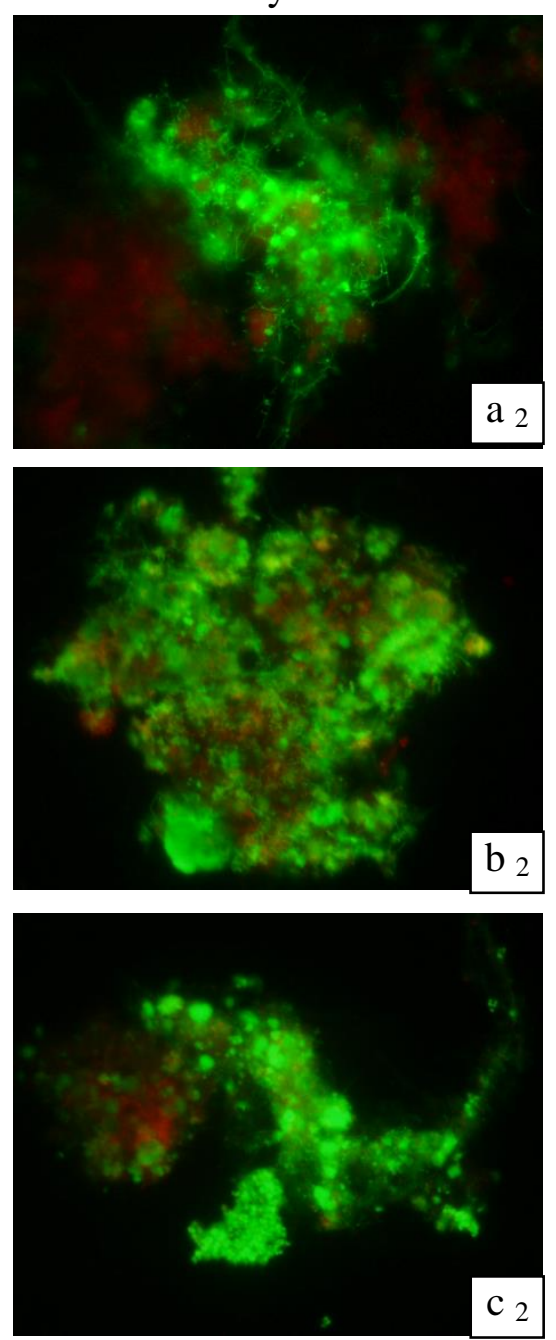

Figure 5. Microscopic images of viability tests of activated sludge from SBR 1 (a), SBR 2 (b) and SBR 3 (c) after 7 and 35 days of SBRs operation, 400X

It has to be commented that the uncoupling mechanisms are not well known [1] and moreover, contradictory results can be found in literature. Unlike other authors, in the present work sludge reduction values were found less significant than those reported in other articles. Thus, Qiong et al. (2013) concluded that adding $3 \mathrm{mg} / \mathrm{L}$ of pNP, a reduction of $62 \%$ in the average sludge generation rate was achieved after 45 operation days [21]. On the other hand, [12,22] who worked with higher uncoupler concentration $(100 \mathrm{mg} / \mathrm{L})$, reported a sludge reduction of $49 \%$. The drawback they 
found was that the substrate removal efficiency decreased $28.7 \%$ and the biomass yield decreased $30 \%$.

However, the use of the uncouplers should be thoroughly studied due to their hazardous nature as some authors point out [11]. This is the reason why new more eco-friendly chemicals have to be studied with the aim of reducing sludge with less environmental impact.

Concerning respirometric analysis, the heterotrophic biomass yield coefficient achieved after the respirometry tests were $0.498,0.464$ and 0.423 for the SBR 1 (control), SBR 2 (pNP) and SBR 3 (LODOred), respectively at the end of the experiments (Table 4). The lower yield in the SBR 2 and SBR 3 suggests that biomass is using more energy than biomass in SBR 1 in order to overcome eventual toxicity effects due to pNP accumulation (in SBR 2) by adsorption on the biomass flocs. That means that uncoupling metabolism is occurring at a certain extent. In the case of SBR 3 , activated sludge is subjected to extended organic matter limitation due to the formation of wrapped flocs as proved in section 3.2. This leads to biomass decay reducing cell production. Thus, YH of biomass in SBR 3 is lower than those measured for biomass of the other reactors since the energy obtained from catabolism is used in motility, materials transport and other basic activities. This is named maintenance metabolism $[23,24]$.

Concerning OUR measurements, it has to be highlighted that the differences among the measured OUR for the biomass of the three reactors are negligible. Thus, cells activity is very similar in the three reactors and results are in concordance with those obtained in the viability tests reported above. 
Table 4. Heterotrophic biomass yield coefficient $\left(\mathrm{g}_{\mathrm{COD}} / \mathrm{g}_{\mathrm{COD}}\right)$ measured in the respirometric tests

\begin{tabular}{ccc}
\hline SBR & \multicolumn{2}{c}{$\mathrm{Y}_{\mathrm{H}}$} \\
\hline Day & 7 & 30 \\
\hline SBR 1 & 0.540 & 0.498 \\
SBR 2 & 0.518 & 0.464 \\
SBR 3 & 0.522 & 0.423 \\
\hline
\end{tabular}

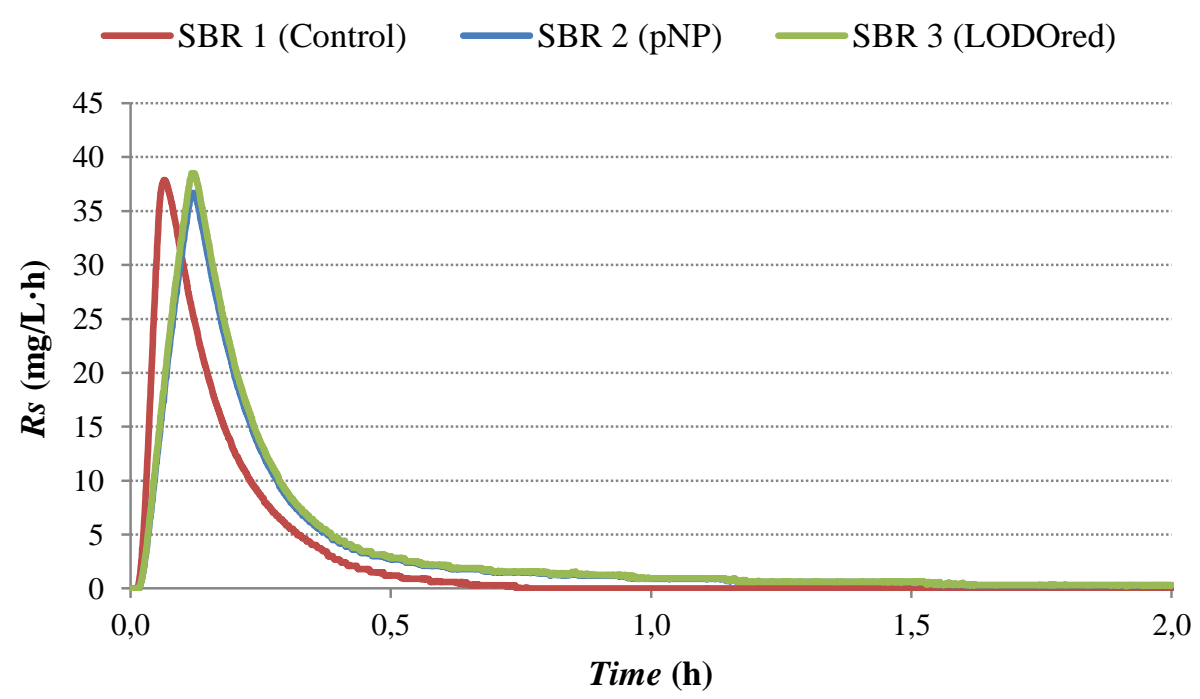

Figure 6. Respirograms obtained with the sludge from SBR 1 and SBR 2

\section{Conclusions}

In this work, the reduction of the secondary sludge production was evaluated in SBRs by the addition of pNP and a commercial product (LODOred).

LODOred reagent reduced the sludge production (26.2\%) without affecting COD removal efficiency $(96 \%)$ in comparison with the control reactor. This reagent also improved the settleability of the mixed liquor.

Contrary to the expected results found in the literature, sludge production for SBR2 containing para-nitrophenol was low in comparison with the sludge production in the control SBR. 
Results showed that the higher protein concentration, the higher DNA concentration was present in the effluent. However, for all SBRs, no direct connection was found between sludge production values and protein, carbohydrate and DNA concentrations.

Further experiments at a higher scale should be carried out with a wider range of chemicals concentrations both with synthetic and municipal wastewater to reinforce the results.

\section{Acknowledgements}

This work was supported by Universitat Politècnica de València (Project reference: PAID-05-12).

\section{References}

[1] Y. Wei, R.T. Van Houten, A.R. Borger, D.H. Eikelboom, Y. Fan, Minimization of excess sludge production for biological wastewater treatment, Water Res. 2003, 37, 4453-4467.

[2] G.U. Semblante, F.I. Hai, H.H. Ngo, W. Guo, S.-J. You, W.E. Price, et al., Sludge cycling between aerobic, anoxic and anaerobic regimes to reduce sludge production during wastewater treatment: performance, mechanisms, and implications, Bioresour. Technol. 2014, 155, 395-409.

[3] M. Coma, S. Rovira, J. Canals, J. Colprim, Minimization of sludge production by a side-stream reactor under anoxic conditions in a pilot plant, Bioresour. Technol. 2013, 129, 229-35. 
[4] P. Foladori, S. Tamburini, L. Bruni, Bacteria permeabilization and disruption caused by sludge reduction technologies evaluated by flow cytometry, Water Res. 2010, 44, 4888-99.

[5] A. Khursheed, a a Kazmi, Retrospective of ecological approaches to excess sludge reduction, Water Res. 2011, 45, 4287-310.

[6] E. Zuriaga-Agustí, A. Bes-Piá, J.A. Mendoza-Roca, G. Garrido-Mauri, J.L. Alonso-Molina, Reduction of the sludge production in a sequencing batch reactor by addition of chlorine dioxide: Influence on the process performance, Chem. Eng. J. 2012, 209, 318-324.

[7] S. Isazadeh, M. Feng, L.E. Urbina Rivas, D. Frigon, New mechanistically based model for predicting reduction of biosolids waste by ozonation of return activated sludge, J. Hazard. Mater. 2014, 270, 160-8.

[8] G. Wang, J. Sui, H. Shen, S. Liang, X. He, M. Zhang, et al., Reduction of excess sludge production in sequencing batch reactor through incorporation of chlorine dioxide oxidation, J. Hazard. Mater. 2011, 192, 93-8.

[9] P. Foladori, G. Andreottola, P. Ziglio, Sludge Reduction Technologies in Wastewater Treatment Plants, IWA Publishing, 2010.

[10] Y. Liu, J.H. Tay, Strategy for minimization of excess sludge production from the activated sludge process, Biotechnol. Adv. 2001, 19, 97-107.

[11] W.-Q. Guo, S.-S. Yang, W.-S. Xiang, X.-J. Wang, N.-Q. Ren, Minimization of excess sludge production by in-situ activated sludge treatment processes--a comprehensive review, Biotechnol. Adv. 2013, 31, 1386-96. 
[12] E.U. Low, H.A. Chase, M.G. Milner, T.P. Curtis, Uncoupling of metabolism to reduce biomass production in the activated sludge process, Water Res. 2000, 34, 3204-3212.

[13] X.-C. Feng, W.-Q. Guo, S.-S. Yang, H.-S. Zheng, J.-S. Du, Q.-L. Wu, et al., Possible causes of excess sludge reduction adding metabolic uncoupler, 3,3',4',5-tetrachlorosalicylanilide (TCS), in sequence batch reactors, Bioresour. Technol. 2014, 173, 96-103.

[14] Y. Liu, Chemically reduced excess sludge production in the activated sludge process, Chemosphere. 2003, 50, 1-7.

[15] F. Fang, H.-L. Hu, M.-M. Qin, Z.-X. Xue, J.-S. Cao, Z.-R. Hu, Effects of metabolic uncouplers on excess sludge reduction and microbial products of activated sludge, Bioresour. Technol. 2015, 185, 1-6.

[16] APHA, Standard methods for the examination of water and wastewater, 21st ed., American Public Health Association, Washington DC, 2005.

[17] G.W. Ramírez, J.. Alonso, A. Villanueva, R. Guardino, J.A. Basiero, I. Bernecer, et al., A rapid, direct method for assessing chlorine effect on filamentous bacteria in activated sludge, Water Res. 2000, 34, 3894-3898.

[18] G. Ricco, M.C.M.C. Tomei, R. Ramadori, G. Laera, Toxicity assessment of common xenobiotic compounds on municipal activated sludge: comparison between respirometry and Microtox, Water Res. 2004, 38, 2103-10. 
[19] F. Rezouga, M. Hamdi, M. Sperandio, Variability of kinetic parameters due to biomass acclimation: case of para-nitrophenol biodegradation, Bioresour. Technol. 2009, 100, 5021-5029.

[20] X.F. Yang, M.L. Xie, Y. Liu, Metabolic uncouplers reduce excess sludge production in an activated sludge process, Process Biochem. 2003, 38, 13731377.

[21] T. Qiong, L. Song, Y. Cheng, J.R. Xiong, Improving the performance of membrane bioreactors by adding a metabolic uncoupler, 4-Nitrophenol, Appl. Biochem. Biotechnol. 2013, 169, 2126-2137.

[22] E.W. Low, H.A. Chase, Reducing production of excess biomass during wastewater treatment, Water Res. 1999, 33, 1119-1132.

[23] M.C.M.V.L.X.D.H.Q.L.W. J.Y. Zhu, Microbiological Endogenous Processes in Biological Wastewater Treatment Systems, Crit. Rev. Environ. Sci. Technol. 2010, 40, 239-265.

[24] X. Hao, Q. Wang, Y. Cao, M.C.M. van Loosdrecht, Measuring the activities of higher organisms in activated sludge by means of mechanical shearing pretreatment and oxygen uptake rate, Water Res. 2010, 44, 3993-4001. 


\section{List of Figures}

Figure 1. Scheme of the laboratory sequencing batch reactors

Figure 2. para-Nitrophenol toxicity test

Figure 3. Sludge production between withdrawals during the SBRs operation time

Figure 4. Protein and DNA concentration in the SBRs effluent

Figure 5. Microscopic images of viability tests of activated sludge from SBR 1 (a), SBR 2 (b) and SBR 3 (c) after 7 and 35 days of SBRs operation, 400X

Figure 6. Respirograms obtained with the sludge from SBR 1 and SBR 2

\section{$\underline{\text { List of Tables }}$}

Table 1. Strategy of SBR operation: phases duration and operating parameters.

Table 2. Characteristics of SBR effluent

Table 3. Comparison in dead cells percentage in the three SBRs

Table 4. Heterotrophic biomass yield coefficient $\left(\mathrm{g}_{\mathrm{COD}} / \mathrm{g}_{\mathrm{COD}}\right)$ measured in the respirometric tests 